\title{
NESTING SWALLOWS ON THE GO
}

\author{
DONALD F. HOOPER, Box 40, Somme, Saskatchewan. SOE 1 N0 and FRANK \\ SWITZER, 1301 Shannon Road, Regina, Saskatchewan. S4S 5K9
}

In this rush and go age Barn Swallows are really getting into the swing of things and have been found nesting in mobile situations.

On 9 August 1991, Phillip Peterson and Grant Chase were putting up hay on Chase's ranch, along the Piwei River meadow south of Somme. Phillip drove the 4020 John Deere tractor four $\mathrm{km}$ from the ranch corrals and proceeded cutting hay with the haybine. As he went around the meadow he wondered why a pair of Barn Swallows were diving in front of the window of the tractor cab. When he stopped he found that they had a nest with four young above the windshield, under the overhang of the cab roof. As he drove along the meadow the adult birds, who had followed from the ranch yard, were feeding the young on the go.

The river meadow is rough with beaver and muskrat holes and it is a wonder that the young weren't bounced out of the nest. Also, to withstand such jarring, the nest must have been attached to the cab with "super glue."

The adults stayed right with the tractor and fed the young on the move each day as the hay was being cut and baled, along five $\mathrm{km}$ of river meadow. The four young remained healthy and in time left the nest, apparently none the worse for the roaring lullaby of a diesel tractor with its fumes and smoke. Instead of gentle rocking there was the rugged treatment of shaking, jolting and bouncing.

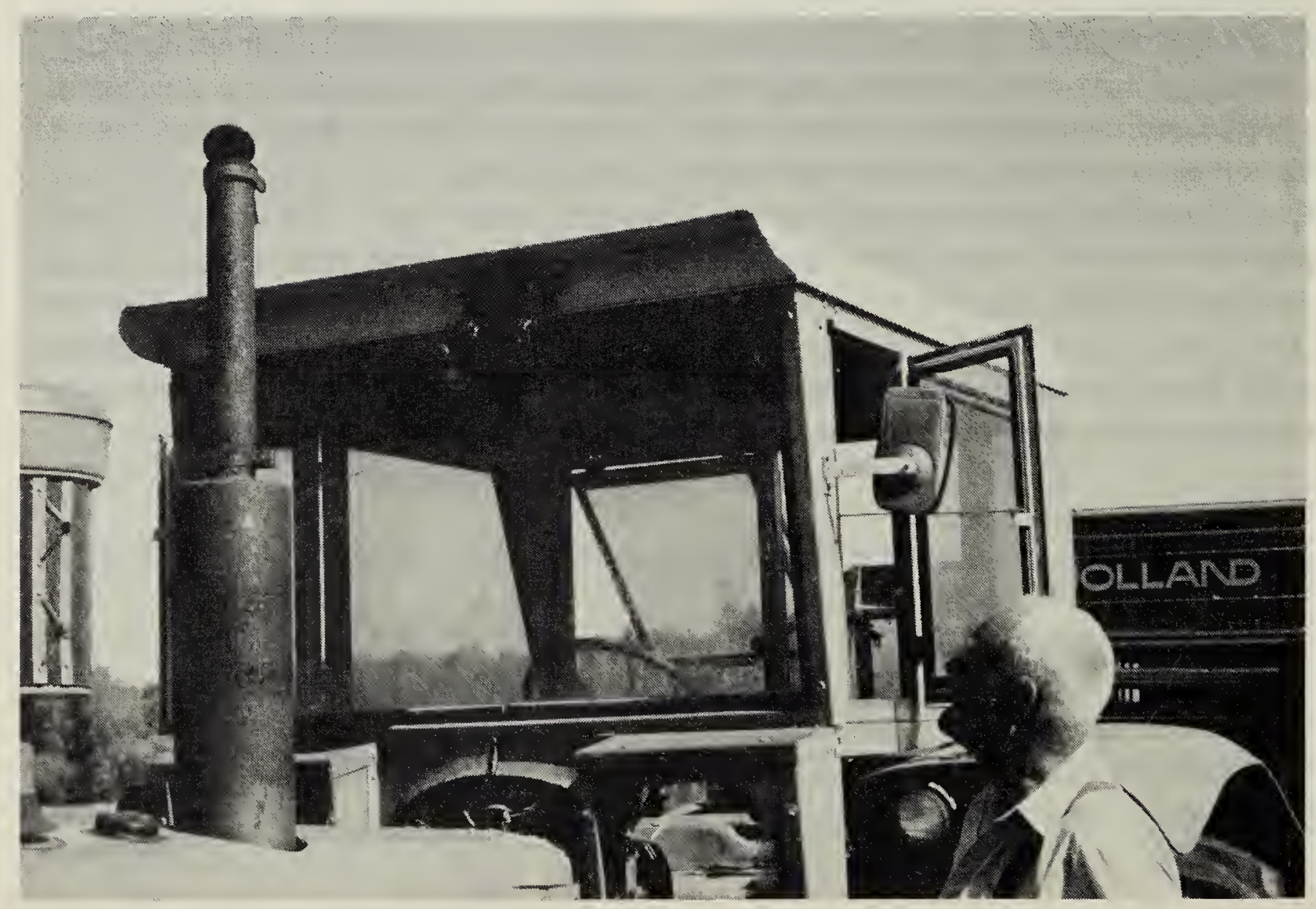

Grant Chase is puzzled about his haying companions.

Donald F. Hooper 


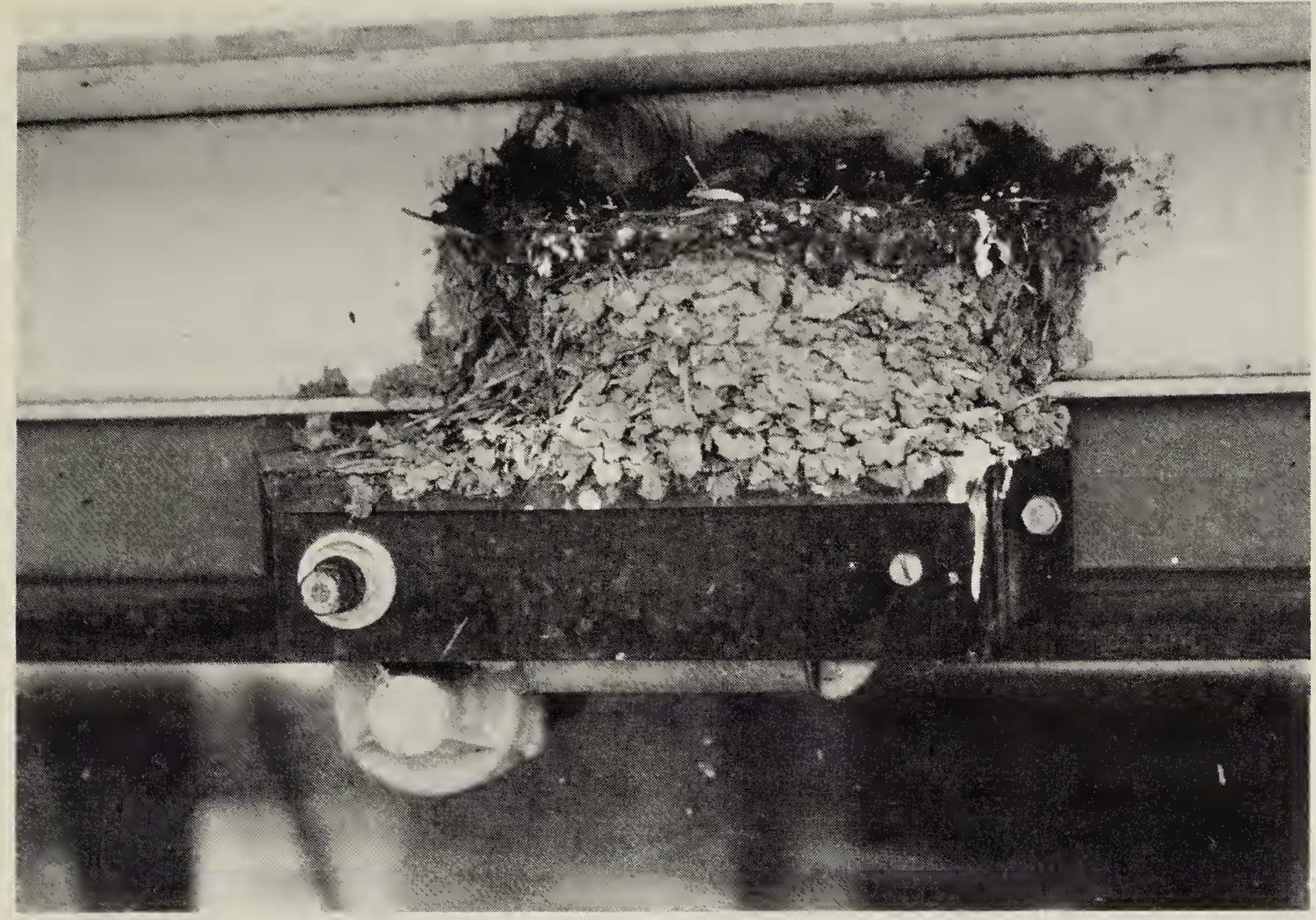

Barn Swallow nest on tractor cab.

Donald F. Hooper

The eagle as a symbol of reincarnation appears in the Bible: where the Psalms say "Thy youth is renewed like the eagle's," the reference is to the belief that every ten years the eagle soars into the sky and into the flaming sun itself, then plunges into the sea where it moults and reemerges with new plumage and new life. Dennis Bardens. 1987. Psychic Animals. Holy, NY.

The whole secret of the study of nature lies in learning how to use one's eyes.

George Sand. 